\title{
GASTRO INTESTINAL PARASITES OF MUSK DEER (MOSCHUS CHRYSOGASTER HODGSON, 1839) IN LANGTANG NATIONAL PARK, NEPAL
}

\section{Bishnu Achhami, Hari Prasad Sharma and Ashok Bahadur Bam}

Journal of Institute of Science and Technology

Volume 21, Issue 1, August 2016

ISSN: 2469-9062 (print), 2467-9240(e)

Editors:

Prof. Dr. Kumar Sapkota

Prof. Dr. Armila Rajbhandari

Assoc. Prof. Dr. Gopi Chandra Kaphle

JIST, 21 (1), 71-75 (2016)

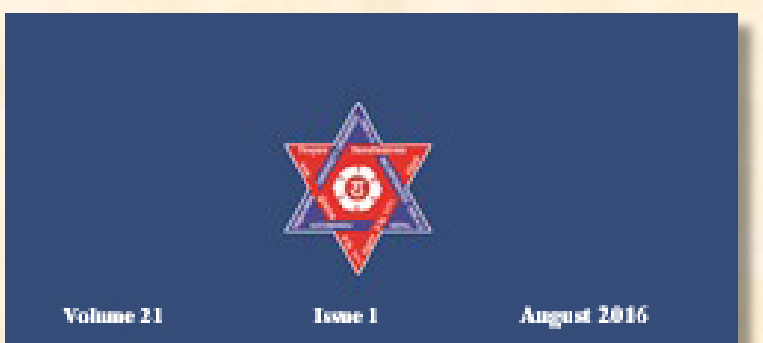

JOURNAL OF INSTITUTE OF SCIENCE AND TECHNOLOGY
Published by

Institute of Seience and Teehnology

Tribhuvan University

Kirtipur, Kathmanda, Nepal

Published by:

Institute of Science and Technology

Tribhuvan University

Kirtipur, Kathmandu, Nepal 


\title{
GASTRO INTESTINAL PARASITES OF MUSK DEER (MOSCHUS CHRYSO- GASTER HODGSON, 1839) IN LANGTANG NATIONAL PARK, NEPAL
}

\author{
Bishnu Achhami, Hari Prasad Sharma and Ashok Bahadur Bam* \\ Central Department of Zoology, Tribhuvan University, Kirtipur, Nepal \\ *Crossponding email: ashokbam@gmail.com
}

\begin{abstract}
This study was carried out to determine the prevalence of gastrointestinal parasites of musk deer in Langtang National Park, Nepal. A total of 9 fecal samples were collected systematically and analyzed using standard procedures during May-June, 2014. Overall 7 species of parasites including 4 nematodes, 1 cestode, 1 trematode and 1 protozoan parasite were recorded. Prevalence of Ascaris sp. was high (88.89\%) followed by Eimeria sp. (77.78\%), Trichuris sp. (66.67\%), Strongyloides sp. (55.56\%), Moniezia sp. (44.44\%), Strongyle (44.44\%) and Paramphistomum sp. (44.44\%). Most of the samples had heavy parasitic infestation and multiple parasites were also observed in same individual. The high parasitic prevalence might have adverse health impact on musk deer. The possibility of cross-transmission of parasites between livestock and wildlife in Langtang National Park should be studied in future.
\end{abstract}

Key words: Wild animal, Gastrointestinal parasites, Ascaris, Mixed infection, Prevalence

\section{INTRODUCTION}

Musk deer (Moschus chrysogaster) is a globally threatened species listed as "Vulnerable" in IUCN Red Data Book (Wang \& Harris 2008). As per national status, it is an endangered species and is listed in appendix I of CITES (Wang \& Harris 2008, Jnawali et al. 2011). In Nepal, musk deer is found in Api Namppa Conservation Area, Khaptad National Park, Rara National Park, Shey Phoksundo National Park, Dhorpatan Hunting Reserve, Annapurna Conservation Area, Manaslu Conservation Area, Langtang National Park, Makalu Barun National Park and Kanchanjunga Conservation Area (Baral \& Shah 2008, Aryal et al. 2010, Aryal and Subedi 2011, Jnawali et al. 2011). Its population is declining due to anthropogenic activities such as habitat loss, habitat degradation and poaching (Wang \& Harris 2008, Jnawali et al. 2011). Disease is another possible detrimental factor for population declining of mammal (Pedersen et al. 2007) because these are reservoirs of several parasites. For examples, red fox (Vulpes vulpes) harbors different intestinal nematodes and trematodes (Richards et al. 1995) and rodents like Microtus oeconomus and M. agrestis have Babesia microti (Karbowiak et al. 1999). Interaction of these animals in common ecosystem may play significant role for transmission of parasites among different species (Bengis et al. 2002, Smith et al. 2009). The role of parasites in wildlife population decline is not well documented. However, parasites occurrence, mode of infection and possible impacts in wildlife are documented, mostly using samples from dead animals and from zoo samples (Polley 2005, Zhang et al. 2008, Bertelsen et al. 2010, De Craeye et al. 2011, Veronesi et al. 2016). In Nepal, only few baseline surveys on wildlife are documented so far on parasite prevalence and interaction with livestock. In particular, parasitic prevalence in rhesus monkey (Macaca mulata), Assamese macaque (Macaca assamensis), red panda (Ailurus fulgens), interaction of red panda and livestock and crossinfection of Schistosoma between elephant and rhinoceros are reported (Jha et al. 2011, Byanju et al. 2011, Devkota et al. 2012, Shrestha \& Bindari 2013, Tachibana et al. 2013, Pokheral \& Maharjan 2014, Lama et al. 2015, Sharma et al. 2016). These studies opened the possibilities of conservation threats to wild animals in Nepal from parasites related mortalities reported elsewhere in red wolf (Canis rufus), grey wolf (C. lupus), wolverine (Gulo gulo), brown bear (Ursus arctos), primates, and giant panda (Ailuropoda melanoleuca) (Custer \& Pence 1981, Phillips \& Scheck1991, Chapman et al. 2006, Morner et al. 2005, Zhang et al. 2008). So far, we do not have any baseline data of parasitic prevalence in 
globally threatened rare species-the musk deer of Nepal. Hence, this study was aimed to determine the prevalence of gastrointestinal parasite in musk deer of Langtang National Park, Nepal.

\section{MATERIALS AND METHODS}

\section{Study area}

This study was carried out in May-June of 2014 in Langtang National Park (LNP) of central Nepal. LNP $\left(28^{\circ} 10^{\prime} 25^{\prime \prime} \mathrm{N}, 85^{\circ} 33^{\prime} 11^{\prime \prime} \mathrm{E}\right)$ covers the area of $1,710 \mathrm{~km}^{2}$ and was established in 1976. It has vegetation like birch (Betula utilis), rowan (Sorbus microphyla), oak (Quercus semecarpifolia), fir (Abies spectabilis), juniper (Juniperus recurva), maple (Acer caudatum, A. pectinatum), rhododendron spp., bamboos (Himalaya calamus falconeri, Thamno calamus aristatus) and wildlife fauna such as Himalayan black bear ( $U$. thibetanus), common leopard (Panthera pardus), musk deer (M. chrysogaster), goral (Nemorhaedus goral), Himalayan tahr (Hemitragus jemlahicus), red panda (A. fulgens), wild boar (Sus scrofa), wild dog (Cuon alpinus), snow leopard (Uncia uncia). Human settlement is common practice inside the park and the intensity of human activities, including livestock grazing, made it an ideal study site to explore anthropogenic influences on host-parasite dynamics in musk deer.

\section{Sample collection and lab process}

A total of 9 fecal samples were collected in this study. For sample collection, four horizontal transects were established starting from $3,000 \mathrm{~m}$ and with an interval of $200 \mathrm{~m}$ up to $3,600 \mathrm{~m}$ of elevation. Approximately $20 \mathrm{gm}$ of fresh fecal samples, covered with moist mucous, were collected in each sampling. A minimum distance of 300-400 $\mathrm{m}$ was maintained in subsequent sampling to avoid collecting samples from same individual. Samples were collected in a $50 \mathrm{ml}$ sterile vial containing $10 \%$ ethyl alcohol and then transported to the laboratory of Central Department of Zoology, Tribhuvan University, Kathmandu and stored at $4^{\circ} \mathrm{C}$ before processing. Samples were processed by standard zinc salt sedimentation-floatation technique (Soulsby 1982). Eggs and cysts were identified as mentioned in Yamaguti (1961), Soulsby (1982) and Zajac and Conboy (2012). Data were analyzed using descriptive statistics in MSExcel, 2007. The parasitic prevalence was determined as the number of species found in samples divided by total number of samples observed. Similarly, the intensity of parasitic prevalence as light, mild, medium and heavy was determined based on the number of eggs or oocysts observed per microscopic field.

\section{RESULTS}

Of all the tested samples, $88.89 \%$ samples were positive for gastrointestinal parasites in this study. Four species of nematodes (Ascaris sp., strongyle, Strongyloides sp. and Trichuris sp.), one cestode (Moniezia sp.), one trematode (Paramphistomum sp.) and protozoa (Eimeria sp.) parasites were observed in feces of musk deer (Fig. 1). Ascaris sp. was the most prevalent parasite observed in $88.89 \%$ samples. Both of the Eimeria (with micropyle and without micropyle) had the equal prevalence of $77.78 \%$. Similarly, Trichuris sp., Strongyloides sp., strongyle, Moniezia sp. and Paramphistomum sp. had percentage prevalence of $66.67,55.56,44.44$, 44.44 and 44.44 respectively. All of the nine samples revealed eggs/cysts of two or more parasites (Table 1). Heavy infection was considered if the sample containing five or more than five eggs or oocysts were observed per field. Strongyloides sp., Trichuris sp., Moniezia sp. and Paramphistomum sp. showed the light infection in most of the samples (Table 2).

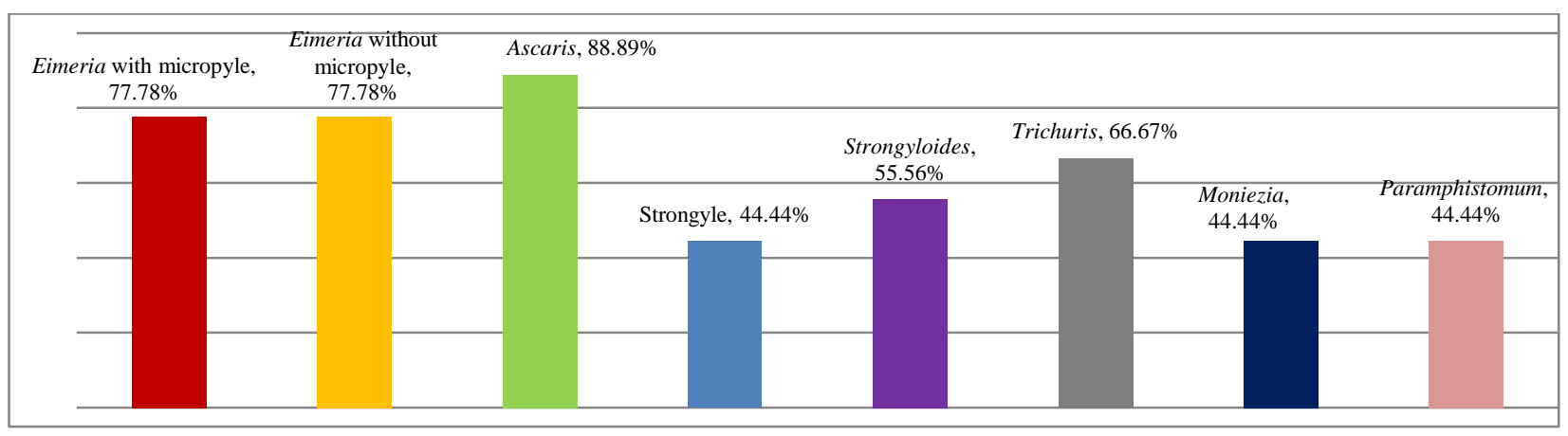

Fig 1: Species wise prevalence of gastrointestinal parasites in musk deer. 
Table 1: Combination of multiple gastrointestinal parasites observed in feces of musk deer

\begin{tabular}{|l|c|c|}
\hline Name of the parasites & No. of case & Prevalence (\%) \\
\hline Eimeria, Ascaris, Trichuris, strongyle, Strongyloides & 3 & $33.33 \%$ \\
\hline Eimeria, Ascaris, Trichuris, strongyle, Paramphistomum & 2 & $22.22 \%$ \\
\hline Eimeria, Ascaris, Trichuris, strongyle & 4 & $44.44 \%$ \\
\hline Eimeria, Ascaris, Moniezia, strongyle & 2 & $22.22 \%$ \\
\hline
\end{tabular}

Table 2: Intensity of parasitic prevalence in feces of musk deer

\begin{tabular}{|l|c|c|c|c|}
\hline \multicolumn{1}{|c|}{ Name of Parasite } & + (Light) & $++($ Mild $)$ & $+++($ Medium $)$ & $++++($ Heavy) \\
\hline Eimeria with micropyle & 1 & 1 & 2 & 3 \\
\hline Eimeria without micropyle & - & 2 & 1 & 4 \\
\hline Ascaris sp. & - & 4 & 1 & 3 \\
\hline Strongyle & - & 2 & - & 2 \\
\hline Strongyloides sp. & 2 & - & 3 & - \\
\hline Trichuris sp. & 4 & 1 & 1 & - \\
\hline Moniezia sp. & 3 & - & 1 & 2 \\
\hline Paramphistomum sp. & 2 & - & - & \\
\hline
\end{tabular}

\section{DISCUSSION}

The parasitic prevalence was $88.89 \%$ in this study. Heavy infestation was observed for Ascaris and Eimeria sp. Eimeria sp. can be a severe problem because it causes bloody diarrhea in herbivore (Mass 2007). Sharma et al. (2016) previously documented high prevalence of coccidian parasites in chauri (Hybrids of Yak and cow) from this area. Since this study area also belongs to the livestock grazing sites, occurrence of Eimeria may be due to mutual transmission between livestock and musk deer or vice versa. In this study, prevalence of nematode was found to be higher compared to cestode and trematode, which was similar to earlier reports in roe deer of lower Silesia (Pacon 1994) and in red deer and fallow deer in Spain (Santin et al. 2004). Similar to musk deer, higher prevalence of Trichuris, Ascaris and coccidian were reported previously in spotted deer (Varadharajan \& Kandasamy 2000). The high frequency of nematodes may cause iron deficiency anemia and abdominal disorders, which can have significant impact on rare species like musk deer (Roche 1988). Prevalence of Paramphistomum sp. was $44.44 \%$ in this study, which was slightly less than the report of Rehman et al. (2014) where they showed $36.5 \%$ prevalence in 21 herbivore zoo species in Bangladesh. Paramphistomum generally occurs in rumen, reticulum and small intestine and cause intestinal wall erosions, haemorrhage, oedema and necrosis of ruminal papillae (Love \& Hutchinson 2003).The infection of Ascaris sp. may be through soil intake by grazing animals. The thick outer shell of
Ascaris sp. facilitates up to 15 years survival in soil and causes diarrhea, malnutrition and obstruction of intestine (Hagel \& Giusti 2010). However, the presence of multiple parasites in an individual increases parasitic load and can have adverse impact on health. Prevalence of Strongyloides, which causes diarrhea, anorexia, weight loss, variable anaemia and dyspnoea, has been reported in deer in several previous reports (Ezenwa 2003, Meshram et al. 2008, Gupta et al. 2011). Strongyloides prevalence may be due to wet, muddy conditions of pasturing land. Strongyle was also prevalent in musk deers which can cause inappetence, intermittent watery diarrhoea and weight loss.

\section{CONCLUSION}

This study showed that musk deer in Langtang National Park, Nepal have high prevalence of gastrointestinal parasites including nematodes, trematodes, cestodes and protozoa. For most of the parasites the parasitic load was high and each musk deer was infested with multiple parasites. The high prevalence of multiple parasites might have significant health impact in musk deer and possibly play direct or indirect role in its population decline. The cross transmission of parasites between livestock and wildlife is possible in LNP which should be explored in future studies.

\section{ACKNOWLEDGEMENTS}

The authors are thankful to the Department of National Parks and Wildlife Conservation, Nepal for 
permitting this research. Authors thank to Bishnu Bajgain, Dipendra Adhikari, and staff of Langtang National Parks for their support. Authors are grateful to Central Department of Zoology, Tribhuvan University for providing laboratory facility. The first author would like to thank CAS - TU (Chinese Academy of Science - Tribhuvan University, Institute of Science and Technology) for providing Master's thesis grant. Authors also would like to thank Rufford Small Grant Foundation for research grant.

\section{REFERENCES}

Aryal, A., Raubreheimer, S., Subedi, S. and Kattel, B. 2010. Spatial habitat overlap and habitat preference of Himalayan Musk Deer in Sagarmatha National Park, Nepal. Current Research Journal of Biological Sciences 2: 217-225.

Aryal, A. and Subedi, A. 2011. The conservation and potential habitat of the Himalayan Musk Deer, $M$. chrysogaster, in the protected areas of Nepal. International Journal of Conservation Science 2: 127-141.

Baral, H.S. and Shah, K.B. 2008. Wild mammals of Nepal. Himalayan Nature, Kathmandu. pp.188

Bengis, R. G., Kock, R. A. and Fischer, J. 2002. Infectious animal diseases: the wildlife/livestock interface. Revue Scientifiqueet Technique-Office international des epizooties 21(1): 53-66.

Bertelsen, M. F., Meyland-Smith, F., Willesen, J. L., Jefferies, R., Morgan, E. R. and Monrad, J. 2010. Diversity and prevalence of metastrongyloid nematodes infecting the Red Panda (Ailurus fulgens) in European zoos. Veterinary Parasitology 172: 299-304

Byanju, R., Shrestha, S. P. and Khanal, D. R., 2011. Prevalence of Gastrointestinal Parasites in Yaks of Lehe VDC, Manaslu Conservation Area. Nepalese Journal of Science and Technology 12: 366-369.

Chapman, C. A., Wasserman, M. D., Gillespie, T. R., Speirs, M. L., Lawes, M. J., Saj, T. L. and Ziegler, T. E. 2006. Do food availability, parasitism, and stress have synergistic effects on red colobus populations living in forest fragments? American Journal of Physiology and Anthropology 131: 525-534.

Custer, J. W. and Pence, D. B. 1981. Ecological analyses of helminth populations of wild canids from the Gulf coastal prairies of Texas and Louisiana. Journal of Parasitology 67: 289-307.
De Craeye, S., Speybroeck, N., Ajzenberg, D., Dardé, M. L., Collinet, F., Tavernier, P., Van Gucht, S., Dorny, P. and Dierick, K. 2011. Toxoplasma gondii and Neospora caninum in wildlife: common parasites in Belgian foxes and Cervidae? Veterinary Parasitology 178(1): 64-69.

Devkota, R., Brant, S. V., Thapa, A. and Loka, E. S. 2012 Sharing schistosomes: the elephant schistosome Bivitello bilharzianairi also infects the greater one-horned rhinoceros (Rhinoceros unicornis) in Chitwan National Park, Nepal. Journal of Helminthology 63: 374-380.

Ezenwa, V. O. 2003. Habitat overlap and gastrointestinal parasitism in sympatric African bovids. Parasitology 126: 379-388.

Gupta, A., Dixit, A. K., Dixit, P., Mahajan, C. and Shrivastava, A.B. 2011. Journal of Threatened taxa 3(11): 2226-2228.

Hagel, I. and Giusti, T. 2010. Ascaris lumbricoides: an overview of therapeutic targets. Infectious disorders drug targets. Bentham Science Publishers 10(5): 349-367.

Jha, A., Chalise, M. K., Shrestha, R. M. and Karki, K. 2011 Intestinal parasitic investigation in temple Rhesus monkeys of Kathmandu. Initiation 4: 1-7.

Jnawali, S. R., Baral, H. S., Lee, S., Acharya, K. P., Upadhyay, G. P., Pandey, M. et al. 2011. The status of Nepal mammals: The National Red List Series. Department of National Parks and Wildlife Conservation Kathmandu, Nepal.

Karbowiak, G., Stanko, M., Rychlik, L., Nowakowski, W. and Siuda, K. 1999. The new data about zoonotic reservoir of Babesia microti in small mammals in Poland. Acta Parasotologica 44: 142-144.

Lama, S. T., Lama, R. P., Regmi, G. R. and Ghimire, T.R. 2015. Prevalence of intestinal parasitic infections in free-ranging Red Panda Ailurus fulgens Cuvier, 1825 (Mammalia: Carnivora: Ailuridae) in Nepal. Journal of Threatened Taxa 7(8): 7460-7464.

Love, S. C. J. and Hutchinson, G. W. 2003. Pathology and diagnosis of internal parasites in ruminants. In Gross Pathology of Ruminants, Proceedings 350, Post Graduate Foundation in Veterinary Science, University of Sydney. Sydney Chapter 16: 309-338.

Mass, J. 2007. Coccidiosis in cattle.California cattlemen's magazine. University of California-Davis Veterinary Views. 
Meshram, M. D., Shirale, S. Y. and Khillare, K. P. 2008. Incidence of helminthic infection in Axis Deer. Veterinary World 1(1): 10.

Morner, T., Wriksson, H., Brojer, C., Nilsson, K., Uhlhorn, H., Agren, E., et al. 2005. Diseases and mortality in free ranging brown bear (Ursus arctos), grey wolf (Canis lupus), and wolverine (Gulo gulo) in Sweden. Journal of Wildlife Diseases 41: 298-303.

Pacon, J. 1994: Parasites of mouflons, stags and roe-deer from the Lower Silesia region. Wild Parasitology 40: 279-92.

Pedersen, A. B., Jones, K. E., Nunn, C. L. and Altizer, S.A. 2007. Infectious disease and mammalian extinction risk. Conservation Biology 21: 1269-1279.

Phillips, M. K. and Scheck, J. 1991. Parasitism in captive and reintroduced red wolves. Journal of Wildlife Diseases 27: 498-501.

Pokheral, G. and Maharjan, M. 2014. Gastrointestinal parasites of assamese macaque (Macaca assamensis Hodgson, 1840) in Shivapuri Nagarjun National Park, Kathmandu, Nepal. Journal of Institute of Science and Technology 19: 53-57.

Polley, L. 2005. Navigating parasite webs and parasite flow: emerging and re-emerging parasitic zoonoses of wildlife origin. International Journal for Parasitology 35(11): 1279-1294.

Rehman, S. M., Dey, A. R., Kundu, U. K. and Begum, N. 2014. Investigation of gastrointestinal parasites of herbivores at Dhaka National Zoological Garden of Bangladesh. Jounal of Bangladesh Agricultural University 12(1): 79-85.

Richards, D. T., Harris, S. and Lewis, J. W. 1995. Epidemiological studies on intestinal helminth parasites of rural and urban red foxes (Vulpes vulpes) in the United Kingdom. Veterinary Parasitology 59(1): 39-51.

Roche, M. and Layrisse, M. 1988. The nature and causes of" hookworm anaemia." American Journal of Tropical Medicine and Hygiene 15(6): 1031-102.

Santin, D. M., Alunda, J. M., Hoberg, E. P., Fuente, C. D. L. 2004. Abomasal parasites in wild sympatric cervids, red deer, Cervus elaphus and fallow deer, Dama dama, from three localities across central and western Spain: relationship to host density and park management. Journal of Parasitology 90: 1378-1386.
Sharma, H. P., Shaner, P. J. L., Bam, A. B. and Achhami, B. 2016. Gastrointestinal parasites of sympatric Red Panda and livestock in protected areas of Nepal. 65th International Conference of the Wildlife Disease Association, July 31August 5, New York, USA.

http://programme.exordo.com/wda2016/delegates/p resentation/152/

Shrestha S. and Bindari Y. R. 2013. Prevalence of gastrointestinal parasites in Chauries of Gumdel VDC of Ramechhap District, Nepal. Net Journal of Agricultural Science 1: 73-74.

Smith, K. F., Acevedo-Whitehouse, K. and Pedersen, A. B. 2009. The role of infectious diseases in biological conservation. Animal Conservation 12(1): 1-12.

Soulsby, E. L. J. 1982. Helminthes, Arthropods and Protozoa of domesticated animals $7^{\text {th }}$ ed. Baillier Tindall and Cassel Ltd., London. pp 802.

Tachibana, H., Yanagi, T., Lama, C., Pandey, K., Feng, M., Kobayashi, S. and Sherchand, J.B. 2013 Prevalence of Entamoeba nuttalli infection in wild rhesus macaques in Nepal and characterization of the parasite isolates. Parasitology International 62: 230-235.

Varadharjan, A. and Kandasamy, A. 2000. A survey of a gastrointestinal parasites of wild animals in captivity in the V. O. C. park and mini zoo, Coimbaore. Zoo's Print Journal 15(5): 257-258.

Veronesi, F., Traversa, D., Lepri, E., Morganti, G., Vercillo, F., Grelli, D., 2016. Occurrence of lungworms in European wildcats (Felis silvestris silvestris) of central Italy. Journal of Wildlife Diseases 52(2): 270-278.

Wang, Y. and Harris, R. B. 2008. IUCN Red List of threatened species. Version 2015.2. www.iucnredlist.org Downloaded on 05 July 2015.

Yamaguti, S. 1961. Systema helminthum.The nematodes of vertebrates. Volume III. Interscience publishers incorporation, New York. pp1261.

Zajac, A. M and Conboy G. A. 2012.Veterinary Clinical Parasitology. John Wiley and Sons Publication. pp 368.

Zhang, J. S., Daszak, P., Huang, H. L., Yang, G. Y., Kilpatrick, A. M. and Zhang, S. 2008. Parasite threat to panda conservation. Eco Health Journal 5:6-9. 